\title{
A PANDEMIA DA COVID-19 NA FRONTEIRA AMAZÔNICA: UMA ANÁLISE PRELIMINAR NAS CIDADES-GÊMEAS DE TABATINGA E LETICIA
}

\section{THE COVID-19 PANDEMIC ON THE AMAZONIAN BORDER: A PRELIMINARY ANALYSIS IN THE TWIN CITIES OF TABATINGA AND LETICIA}

\author{
Luís Alberto Miranda Goveia \\ Mestre em Geografia \\ Docente EBTT do Instituto Federal de Educação, Ciência e Tecnologia do Amazonas campus Tabatinga \\ luis.miranda@ifam.edu.br
}

\begin{abstract}
RESUMO
O presente artigo é um estudo preliminar que tem por objetivo analisar a pandemia da Covid-19 na fronteira amazônica entre o Brasil e a Colômbia, mais especificamente nas cidades-gêmeas de Tabatinga e Letícia. Para tanto, busca-se identificar os principais decretos emitidos pelo poder público, tanto municipal, quanto estadual e nacional e verificar seus impactos na circulação de pessoas e tráfego aéreo e os resultados na quantidade de infectados e óbitos por essa doença. Os resultados mostram que Tabatinga e Letícia apresentam considerável crescimento no número de infectados pela Covid-19. Conclui-se que a integração desses espaços com outros centros regionais possibilitada pela rede de transporte aéreo e fluvial acabou contribuindo para a entrada do novo Coronavírus confirmando a inserção dessas cidades ao processo de globalização.
\end{abstract}

Palavras-chaves: Covid-19. Decretos. Fronteira Amazônica. Leticia. Tabatinga

\begin{abstract}
This paper is a preliminary study that aims to analyze the Covid-19 pandemic in the Amazonian border between Brazil and Colombia, more specifically in the twin cities of Tabatinga and Leticia. To this end, it seeks to identify the main decrees issued by the public authorities, both municipal, state and national, and verify their impact on the circulation of people and air traffic and the results in the number of those infected and killed by this disease. The results show that Tabatinga and Letícia show considerable growth in the number of infected by Covid-19. It is concluded that the integration of these spaces with other regional centers made possible by the air and river transport network ended up contributing to the entry of the new Coronavirus, confirming the insertion of these cities in the globalization process.
\end{abstract}

Keywords: Covid-19. Decrees. Amazonian Border. Leticia. Tabatinga.

\section{INTRODUÇÃO}

A expansão do novo Coronavírus no Brasil e no mundo nos permite realizar reflexões geográficas sobre a sua distribuição espacial e seus impactos sobre a população. Apesar dos primeiros casos terem sido notificados nas principais metrópoles nacionais, importados por infectados que voltaram de viagens ao exterior, percebe-se a cada dia a confirmação de casos fora dos grandes centros urbanos, que graças às redes de transporte, estão integradas às mais diversas regiões nacionais e internacionais contribuindo para a expansão da Covid-19.

$\mathrm{Na}$ fronteira amazônica, mais especificamente nas cidades-gêmeas de Tabatinga e Leticia, nota-se o aumento na quantidade de infectados e também de óbitos por essa doença. Diante desse cenário, a análise preliminar aqui realizada, consistirá na revisão de literatura e identificação e teor dos decretos emitidos pelo poder público que constam na base de dados dos sites oficiais de seus governos e os efeitos dessas regulamentações sobre as redes de transporte e circulação de pessoas nessas cidades,

Recebido em: 07/05/2020

Aceito para publicação em: 21/05/2020. 
complementados pelos dados epidemiológicos divulgados pelas respectivas Secretarias de Saúde até o momento, dia 26 de abril de 2020.

Além dessa introdução, apresentaremos a seguir a caracterização das cidades-gêmeas de Tabatinga e Leticia, na terceira seção será abordada a origem e expansão mundial da Covid-19 e sua difusão no Brasil e na Colômbia. Na quarta seção identificam-se os decretos municipais e as medidas de enfrentamento ao novo Coronavírus em Tabatinga e Leticia e a análise dos dados sobre os infectados e óbitos nestas cidades. Por fim, apresenta-se nas considerações finais, as reflexões desse fenômeno ainda em curso e em crescimento no Brasil e no mundo.

\section{AS CIDADES-GÊMEAS DE TABATINGA E LETICIA NA FRONTEIRA AMAZÔNICA}

O Brasil possui, atualmente, $15.719 \mathrm{~km}$ de fronteira com os seguintes vizinhos sul-americanos: Uruguai, Argentina, Paraguai, Bolívia, Peru, Colômbia, Venezuela, Guiana, Suriname, Guiana Francesa. Diante dessa extensa fronteira, foi definida a área de faixa de fronteira que se estende a 150 $\mathrm{km}$ para o interior do território. Nessa área estão localizadas 588 cidades, mas apenas 26 delas constituem cidades-gêmeas.

Na definição da Portaria 125, de 21 de março de 2014 do Ministério da Integração Nacional:

Serão considerados cidades-gêmeas os municípios cortados pela linha de fronteira, seja essa seca ou fluvial, articulada ou não por obra de infraestrutura, que apresentem grande potencial de integração econômica e cultural, podendo ou não apresentar uma conurbação ou semi-conurbação com uma localidade do país vizinho, assim como manifestações "condensadas" dos problemas característicos da fronteira, que aí adquirem maior densidade, com efeitos diretos sobre o desenvolvimento regional e a cidadania (BRASIL, 2014).

Do total de cidades-gêmeas, apenas seis são consideradas cidades-gêmeas conurbadas, pois além de apresentarem a mesma malha urbana, não possuem acidentes geográficos entre elas nem controle de pessoas e mercadorias na linha-limite por elas compartilhada (BENTO, 2015). Dessa forma, as cidades-gêmeas conurbadas de Tabatinga e Leticia são as únicas na faixa de fronteira amazônica.

Na Amazônia, para além de toda a sua riqueza natural já conhecida e ainda a ser descoberta, e de sua grande relevância regional, nacional e internacional, concentrando a maior bacia hidrográfica do mundo, a maior floresta tropical do planeta e elevada biodiversidade, torna-se necessário considerar a cidade enquanto espaço fundamental no desenvolvimento e planejamento da região, conforme Becker (2005, p. 80): "porque nela a população está concentrada, constitui o nó das redes de relações, e pode, inclusive, impedir a expansão demográfica na floresta".

Nesse contexto, no estado do Amazonas, temos como "nó das redes de relações" a emergência das cidades-gêmeas de Tabatinga e Leticia, localizadas respectivamente no Brasil e Colômbia, intrincadas no interior da Floresta Amazônica.

O município brasileiro de Tabatinga está localizado no extremo oeste do estado do Amazonas, na margem esquerda do rio Solimões e com população estimada em 2019 de 65.844 habitantes (IBGE, 2020). Enquanto Leticia é a capital do departamento (forma de organização territorial) do Amazonas na Colômbia, com população estimada para 2020 de 49.737 pessoas, o que representa $62,94 \%$ do respectivo departamento (DANE, 2020).

As cidades-gêmeas de Tabatinga e Leticia são conurbadas e possuem um intenso fluxo entre seus habitantes, apresentando considerável fluidez territorial entre as mesmas e com elevado grau de complementaridade econômica. Apesar dessa marcante integração entre si, as duas cidades estão a mais de $1000 \mathrm{~km}$ de distância de seus centros regionais mais próximos, além de não possuírem acesso rodoviário com o restante dos seus respectivos territórios nacionais. (EUZÉBIO, 2014).

Em relação aos seus fixos e fluxos, a cidade de Tabatinga recebe voos diários, proveniente de Manaus, realizado pela empresa área Azul com quase 6 mil passageiros circulando mensalmente no aeroporto internacional da cidade, que também realiza voos das Forças Armadas, além do transporte de cargas. (INFRAERO, 2020).

Já o transporte fluvial constitui logística fundamental para o abastecimento do município transportando cerca de 86 mil toneladas de cargas anualmente (ANTAQ, 2018) ao mesmo tempo que possibilita a maior parcela da movimentação de passageiros (mais de 100 mil anualmente) entre a cidade e o município vizinho de Benjamin Constant e a capital Manaus. É importante destacar que parte do transporte de cargas que chega a Tabatinga, tem como destino final sua cidade-gêmea colombiana. 
A cidade de Leticia também possui um aeroporto internacional, que recentemente passou por reforma e ampliou sua capacidade de cargas e passageiros, operando com três companhias aéreas e apresentando voos regulares para a capital Bogotá, e outras cidades do país. Segundo o relatório do transporte aéreo colombiano, cerca de 27 mil passageiros circulam pelo aeroporto mensalmente, este modal também contribui para o abastecimento do município e do departamento do Amazonas com considerável movimento de cargas (cerca de 17 mil toneladas mensais) (AEROCIVIL, 2020). É importante destacar que a cidade de Leticia apresenta notável atividade turística, como por exemplo as incursões às reservas naturais da Floresta Amazônica e comunidades indígenas. Além disso, muitos desses turistas atravessam para a cidade brasileira de Tabatinga com a finalidade de realizar compras, notadamente no comércio de calçados.

Diante da proximidade territorial, da expressiva circulação de pessoas entre as duas cidades, do grande intercâmbio de cargas e mercadorias, de ambas apresentarem redes que permitem o intenso fluxo de passageiros com metrópoles nacionais, e por serem as áreas de fronteira espaços de difusão de doenças, conforme pesquisas da área de Geografia da Saúde, é válida a comparação sobre as medidas adotas em meio à pandemia da Covid-19 e consequentemente o total de infectados e de óbitos até o momento (26 de abril de 2020) nas cidades-gêmeas de Tabatinga e Leticia. Para tanto será necessário reconhecer o papel do Estado na adoção de políticas de enfrentamento tanto na esfera federal quanto na estadual e municipal.

\section{A COVID-19: ORIGEM E DISPERSÃO GEOGRÁFICA NO MUNDO, NO BRASIL E NA COLÔMBIA}

O primeiro caso de Covid-19, provocado pelo vírus Sars-Cov-2, foi registrado na China em dezembro de 2019, mais especificamente na cidade de Wuhan, localizada na província de Hubei. Mesmo diante das críticas em relação à transparência sobre as informações da nova doença, o país conseguiu restringir a maior parte dos casos da epidemia à província onde esta surgiu, adotando severas medidas de isolamento social e de enfrentamento ao construir um hospital em 10 dias (FARIAS, 2020). Até o dia 17 de abril foram confirmados 50.533 casos da Covid-19 com 3.869 mortes na cidade de Wuhan, o que representa $60 \%$ dos casos da China. Com a redução do contágio na província, teve início a reabertura do comércio e a flexibilização das medidas de isolamento.

Contudo, a elevada capacidade de transmissão do vírus e a grande circulação de pessoas, possibilitada pelos avanços das redes de transporte, nos diferentes espaços e territórios no atual contexto de globalização, permitiu a difusão da Covid-19 para outras regiões do mundo.

Em meados de março deste ano, a Itália tornou-se o novo epicentro da doença com mais de 75 mil casos. A demora no reconhecimento da gravidade da Covid-19 e o descrédito na velocidade de transmissão podem ser consideradas causas que contribuíram para a expansão do vírus no país, o que causou ao menos 25 mil óbitos até o momento.

Além da China e Itália, diversos países foram afetados, como, por exemplo, Irã, Espanha, Reino Unido e Estados Unidos. Este último tornou-se o novo epicentro da doença no dia 24 de março e no momento (26 de abril) já acumula um total de mais de 960 mil infectados e 54.614 mortes (SILVERMAN, 2020).

Diante do elevado número de casos em diversos países afetados, a Organização Mundial de Saúde (OMS) classificou a situação como pandemia no dia 11 de março de 2020. Esta classificação reflete a expansão e dispersão geográfica da doença que afeta grande número de pessoas pelo mundo (OPAS, 2020). Além disso o anúncio teve como objetivo alertar os países para a adoção de ações ao enfrentamento e contenção do novo Coronavírus.

No Brasil, a confirmação do primeiro caso da Covid-19 ocorreu no dia 26 de fevereiro, em um paciente que voltara de uma viagem internacional da Itália. Os outros casos que foram surgindo também eram diagnosticados em pessoas que haviam realizado viagens internacionais, retornando em voos por São Paulo ou Rio de Janeiro (FARIAS, 2020). Logo, essas duas metrópoles nacionais ganharam destaque por apresentarem os primeiros casos no país e não demorou muito tempo para o início da transmissão comunitária. Um mês depois, o total de infectados confirmados havia saltado para quase 3.000. Neste momento, após dois meses do primeiro caso notificado, temos no Brasil 61.888 pessoas diagnosticadas com a Covid-19.

Já o primeiro óbito por Covid-19 no Brasil foi registrado no dia 17 de março, saltando para 2.141 após um mês e no momento (dez dias após o primeiro mês), já são 4.205 mortos, ou seja, em apenas dez dias, dobrou a quantidade de óbitos pelo novo coronavírus no país 
A restrição de entrada de estrangeiros pelas fronteiras terrestres do Brasil foi realizada pelo governo federal por meio da Portaria n. ${ }^{\circ} 125$ do dia 19 de março de 2020. A medida, contudo, ocorreu após alguns países vizinhos já terem fechado as suas fronteiras. A Portaria n. ${ }^{\circ} 125$ apontou algumas exceções, dentre as quais, ficou expresso que a referido documento não impediria: "o tráfego de residentes de cidades gêmeas com linha de fronteira exclusivamente terrestre." (BRASIL, 2020a). Dessa forma, no que dependesse do Brasil, a circulação entre os moradores de Tabatinga e Leticia não seria restringida.

No dia 27 de março de 2020, ou seja, mais de um mês depois de notificado o primeiro caso de Covid-19 no país, o governo federal emitiu a Portaria n. 152 em que restringe a entrada de estrangeiros pelos aeroportos do Brasil. Essa medida veio após alguns governos estaduais já terem decidido pela suspensão de voos localizados em seus estados (HENRIQUE, 2020). Importante registrar que os aeroportos são "portas de entrada" para a Covid-19 no país, e que a demora dessa decisão gerou várias críticas à Presidência da República e embate com alguns governadores. Além disso, a OMS, autoridades da área de saúde e diversos chefes de Estado no mundo já orientavam a população quanto à necessidade do distanciamento social para diminuir a propagação do novo coronavírus.

O estado de São Paulo, com 20.715 casos, aparece com o maior número de infectados no Brasil, seguido por Rio de Janeiro (7.111), Ceará (5.833), Pernambuco (4.898) e Amazonas (3.833). O primeiro caso no Amazonas, e também o primeiro da Região Norte do país, foi confirmado no dia 13 de março de 2020. A paciente diagnosticada havia voltado de uma viagem realizada para Londres. A partir desse momento o governo estadual informou que estaria monitorando o Aeroporto Internacional de Manaus e recomendou a suspensão de eventos e aglomerações de pessoas.

No dia 17 de março de 2020 o estado do Amazonas publicou decreto adotando a suspensão de eventos com mais de 100 pessoas e de aulas da rede estadual para a região metropolitana e algumas cidades do interior, incluindo Tabatinga, pela sua característica fronteiriça. Dois dias depois foi publicado o Decreto estadual $n .^{\circ} 42.087$ suspendendo as aulas da sua rede escolar em todas as cidades do estado e também o transporte fluvial de passageiros em embarcações, permitindo apenas o transporte de cargas e serviços essenciais como forma de inibir a aglomeração de pessoas (AMAZONAS-BR, 2020), haja visto que o transporte fluvial é a principal rede que possibilita a entrada e saída do Amazonas, além de contribuir para a conexão e integração da capital com as cidades do interior e destas entre si.

A vizinha Colômbia confirmou o primeiro caso de Covid-19 no dia 6 de março, diagnosticado em uma estudante que havia visitado a Itália. No dia 12 de março, o Ministério da Saúde do país declarou estado de Emergência Sanitária.

A primeira morte confirmada no país ocorreu no dia 21 de março de 2020. A vítima era um taxista de 58 anos que havia transportado turistas italianos. Dois dias depois da primeira vítima fatal, o presidente colombiano, Ivan Duque, publicou decreto suspendendo por um mês os voos internacionais.

O governo da Colômbia determinou, através do Decreto n. ${ }^{\circ} 457$, a quarentena total obrigatória a partir do dia 25 de março, restringindo a circulação de seus cidadãos excetuando-se os serviços essenciais de saúde e alimentação, sob risco de prisão ou pagamento de multa. As aulas em escolas e universidades já estavam suspensas desde a semana anterior. O documento também listou os profissionais das áreas e serviços que deveriam ser credenciados e identificados para continuarem realizando sua rotina laboral. O mesmo decreto também determinou a suspensão dos voos domésticos e viagens terrestres (COLÔMBIA, 2020a).

Já o departamento do Amazonas na Colômbia, publicou Decreto n. ${ }^{\circ} 084$ no dia 20 de março convocando os cidadãos a adotarem o isolamento preventivo, voluntário e pedagógico por um período de dois dias (AMAZONAS-CO, 2020a). Outra medida anunciada pelo Departamento do Amazonas, foi a instalação especial de saúde com 40 leitos para atender pacientes diagnosticados com Covid-19.

No dia 8 de abril, o Decreto n. ${ }^{\circ}$ 099, do Departamento do Amazonas, adotou medidas mais rígidas, ordenando o isolamento preventivo obrigatório de toda a população, limitando a circulação de pessoas e veículos exceto em situações para atender aos serviços básicos de saúde e alimentação ou determinados grupos de profissionais. O mesmo decreto também suspendeu o transporte doméstico aéreo e fixou a possibilidade de sanção penal e multa em caso de violação das medidas (AMAZONAS-CO, 2020b). 
Segundo o Ministério da Saúde colombiano, até o dia 26 de abril, o país já havia confirmado 5.379 casos de Covid-19 com 244 mortes. Do total de infectados, 40 estão no departamento do Amazonas, todos em Leticia.

\section{O SURGIMENTO E EXPANSÃO DA COVID-19 NA FRONTEIRA AMAZÔNICA: O CASO DAS CIDADES-GÊMEAS TABATINGA E LETICIA}

Conforme já registrado, as cidades de Tabatinga e Leticia, na fronteira Brasil-Colômbia, não possuem rotas rodoviárias intermunicipais, estaduais ou nacionais, mas mantém conexões com seus respectivos centros regionais, Manaus e Bogotá, através de voos diários e também de embarcações que percorrem o rio Solimões. Essas redes possibilitam a interação e fluxo de pessoas e mercadorias que chegam à região e inevitavelmente também permitiram a entrada do novo Coronavírus.

Em razão da emergência dessa doença no Brasil e no estado do Amazonas, a prefeitura do município de Tabatinga publicou o Decreto n. ${ }^{\circ} 104$ no dia 17 de março de 2020 classificando a situação de Alerta na saúde pública municipal e adotando entre as medidas de prevenção do contágio pelo novo Coronavírus, a suspensão dos eventos promovidos pelo poder público municipal, as atividades escolares e de atendimento ao público da Administração Municipal e suspendendo as férias de servidores da saúde (TABATINGA, 2020a).

No mesmo dia, por determinação do governo federal colombiano, todas as fronteiras terrestres do país foram fechadas até o dia 30 de maio como forma de evitar a disseminação do Coronavírus dentro de seu território (COLÔMBIA, 2020b). A fronteira entre as cidades de Leticia e Tabatinga foi fechada e passou a ter o monitoramento por parte da Polícia Nacional da Colômbia, agentes de imigração e do Exército colombiano. Inicialmente, foi autorizado o tráfego somente com veículos de alimentos e cargas ou da população sem veículos, modificando a dinâmica corrente no cotidiano fronteiriço que possui intenso tráfego de motos, carros e tuk-tuks. Em seguida, as restrições aumentaram permitindo a travessia da fronteira mediante comprovação de acesso à serviços essenciais.

O primeiro caso de Covid-19 na cidade de Tabatinga foi notificado no dia 8 de abril de 2020 pela Secretaria Municipal de Saúde, que afirmou que o paciente veio infectado da capital Manaus. Nesse momento já havia um total de 804 casos confirmados em todo o estado do Amazonas. Considerando, entre vários fatores, a notificação do primeiro caso do novo Coronavírus em Tabatinga, a prefeitura decretou Situação de Emergência confirmando a possível adoção de medidas de isolamento, quarentena, realização compulsória de exames e testes clínicos (TABATINGA, 2020b)

Os voos realizados pela única empresa aérea com destino à Tabatinga, foram suspensos a partir do dia 17 de abril até o dia 4 de maio em atendimento à demanda da Prefeitura, Ministério Público do Amazonas, Defensoria Pública do Estado e da Promotoria de Justiça para conter o avanço do Coronavírus no município se adequando às recomendações estaduais de evitar a circulação de pessoas entre os municípios.

Em 17 de abril de 2020, novo decreto foi divulgado pela Prefeitura de Tabatinga em que restringiu o horário de funcionamento de todo o comércio essencial do município, que inclui supermercados, clínicas médicas particulares e laboratórios, no horário das $5 \mathrm{~h}$ às $15 \mathrm{~h}$, diminuindo o tempo previsto de funcionamento expresso em decreto anterior em que já havia suspendido atividades e estabelecimentos que geravam aglomeração. Além disso, ficou determinada, a suspensão, por quinze dias, das atividades de táxi, transporte coletivos públicos e privados e moto-táxis (TABATINGA, 2020c). Importante ressaltar que esse último, é sem dúvidas, uma das principais formas de transporte na cidade e fonte de renda para dezenas de trabalhadores. O uso de máscaras de proteção tornou-se obrigatório para a entrada em qualquer estabelecimento público ou privado. A prefeitura também suspendeu por sete dias as atividades de feiras e mercados para a realização de desinfecção desses espaços, em virtude da confirmação de casos confirmados da doença em trabalhadores desses locais. Com a exceção de veículos oficiais, de serviços de delivery ou de transporte de doentes, ficou proibida por quinze dias o tráfego em automóveis nas vias públicas.

Ao longo de todo o período, desde que foi divulgado o estado de alerta no município e com os diversos decretos posteriores, a prefeitura de Tabatinga adotou, além das medidas já mencionadas, as seguintes ações de contenção à Covid-19: triagem de passageiros sintomáticos no aeroporto (antes da restrição de voos), fechamento de estabelecimentos que contrariavam a ordem de suspenderem suas atividades e apreensão de veículos que circulavam nas vias públicas.

Esses decretos municipais tiveram grande efeito na circulação de pessoas e tráfego de automóveis transformando a paisagem urbana de Tabatinga, principalmente a Avenida da Amizade que faz a 
ligação com sua gêmea Leticia na Colômbia. Ao mesmo tempo novos comportamento são observados como o uso de máscaras e a lavagem de mãos nas pias improvisadas na entrada dos estabelecimentos comerciais ou mesmo o uso do álcool em gel, conforme orientado pelas autoridades de saúde.

No momento há 67 casos confirmados de Covid-19 em Tabatinga num total de 3.833 em todo o estado. O município aparece como o $6^{\circ}$ mais afetado pela pandemia, atrás de Manaus que com 2.678 casos representa $71 \%$ do total, e Manacapuru, Iranduba, Itacoatiara e Parintins (FVS, 2020). Em todo o Amazonas, já se registram 304 óbitos, dos quais três são de Tabatinga, incluindo um indígena.

A prefeitura de Leticia, diante dos primeiros casos na Colômbia, e antes de qualquer confirmação de infectados na cidade, apresentou um plano de contingência no dia 18 de março, com a proposta de estabelecer estratégias e ações no município em resposta à pandemia do Coronavírus. Dentre as medidas, o documento cita a distribuição de água potável para a população mais vulnerável, a limpeza e desinfecção de espaços públicos e ampla campanha de sensibilização da população.

No dia 27 de março de 2020, o Decreto Municipal n. ${ }^{\circ}$ 47, que considera a população acima de 70 anos como a mais vulnerável, ficou estabelecido o isolamento preventivo desse grupo e restringiu seu acesso permitido apenas para serviços essenciais, sob risco de sanções penais e pecuniárias (LETICIA, 2020a). Nesse momento, o governo colombiano já havia adotado medidas de isolamento obrigatório em todo o país, conforme mencionando anteriormente.

O primeiro caso notificado em Leticia ocorreu no dia 17 de abril e após nove dias já são 40 casos e dois óbitos. No departamento do Amazonas colombiano, Leticia é a única cidade até o momento com registro de infectados.

Apesar da estabilidade no número de infectados nos dias seguintes à confirmação do primeiro caso, a partir do dia 18 de abril, o número de confirmação de diagnósticos de Covid-19 dobrou por três vezes em menos de uma semana em Tabatinga (Gráfico 1). Nos últimos dias, o vírus continua se expandindo atingindo a marca de 67 infectados e já provocou, ao menos, três óbitos. O Ministério da Saúde apresentou dados sobre o novo Coronavírus em todo o país e identificou que na microrregião amazonense do Alto Solimões, a qual Tabatinga está inserida, a taxa de infectados é de 849,7 casos por milhão de habitantes, o que representa a quarta maior incidência de casos de Covid-19 no Norte do país (BRASIL, 2020b).

Gráfico 1 - Total de infectados por Covid-19 em Tabatinga-AM - Brasil (08-26 de abril)

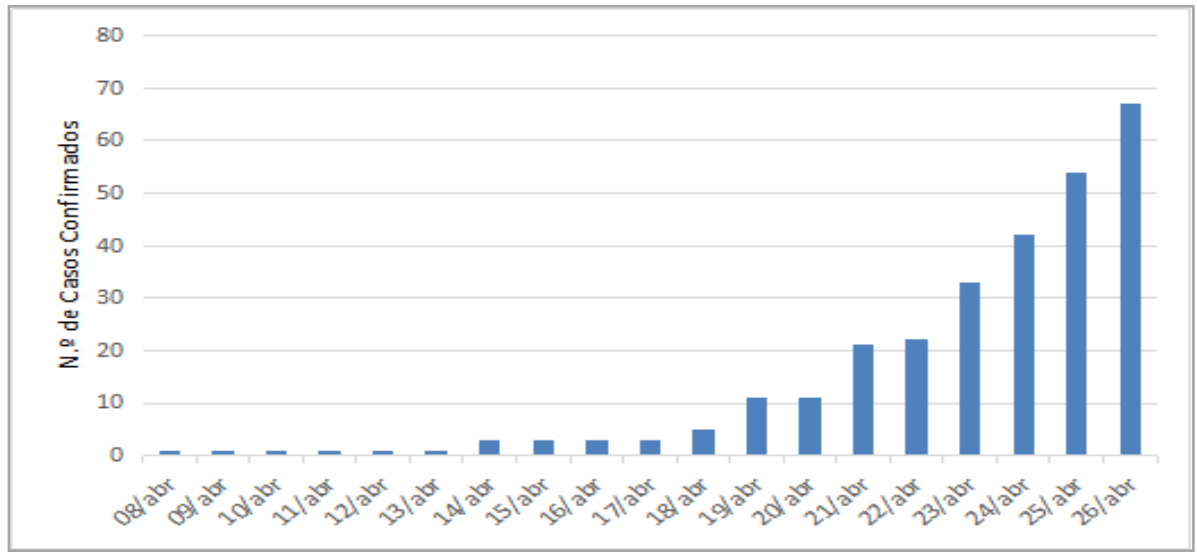

Fonte: Fundação de Vigilância em Saúde - AM - Elaborado pelo autor.

Conforme o gráfico 2, o primeiro caso de Covid-19 em Leticia, foi confirmado após nove dias do primeiro registro em sua cidade-gêmea Tabatinga na fronteira brasileira. Contudo, segue um ritmo de crescimento parecido, com baixa notificação após ao primeiro diagnóstico, mas aumentando em seis vezes o número de casos em apenas cinco dias (21 a 26 de abril).

O último Decreto emitido pelo município de Leticia, confirma o isolamento obrigatório de sua população restringindo a circulação de pessoas e veículos permitindo apenas para serviços essenciais 
como o atendimento médico ou trabalho relacionado ao abastecimento da cidade. A prefeitura organizou um cronograma semanal, relacionando o número final da cédula de cidadania com o dia da semana que a pessoa poderá sair para realizar compras (LETICIA, 2020b) e mantendo a identificação para realização de atividades conforme decreto anterior.

Gráfico 2 - Total de infectados por Covid-19 em Leticia-AM - Colômbia (17-26 de abril)

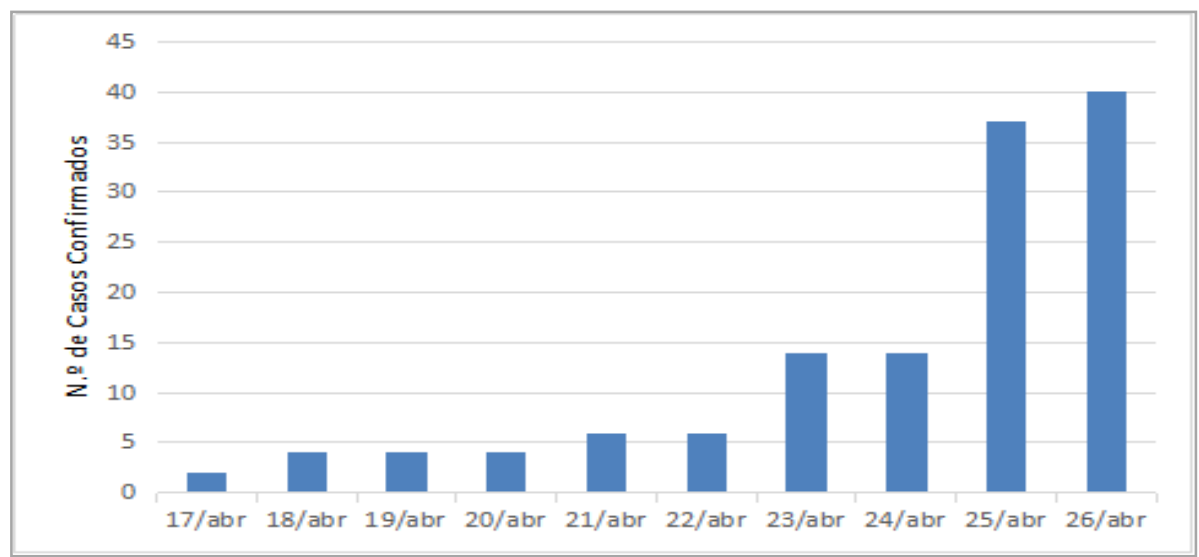

Fonte: Secretaria de Saúde Departamental do Amazonas - Colômbia - Elaborado pelo autor.

No momento, tanto Tabatinga, quanto Leticia tem dependido do transporte aéreo para a transferência de amostras para a realização de testes da Covid-19, que enviam respectivamente para Manaus e Bogotá. Enquanto a primeira se utiliza de voos particulares, a cidade de Leticia é beneficiada pela iniciativa da Federação Nacional de Departamento da Colômbia.

Para além do colapso na saúde do estado do Amazonas causado pela grande quantidade de infectados por Covid-19 na região metropolitana, frequentemente anunciado pela mídia, há também a sobrecarga no sistema de saúde municipal em Tabatinga. Tanto a Unidade de Pronto Atendimento (UPA) quanto o Hospital de Guarnição do Exército no município anunciaram que estão trabalhando com capacidade máxima nos atendimentos que somam os casos comuns mais os infectados pelo novo Coronavírus e solicitaram ajuda do Governo Estadual. Em Leticia, da mesma forma, diante da pequena capacidade do sistema de saúde local e do aumento dos casos de Covid-19, o município solicitou apoio do governo federal para atendimento aos pacientes diagnosticados com o novo Coronavírus.

No dia 07 de abril o governador do Amazonas realizou a aquisição de 19 respiradores para atender os hospitais da capital e no dia 20 do mesmo mês o Ministério da Saúde doou mais 20 respiradores aumentando assim a capacidade de atendimento em Manaus. Outra medida no combate ao novo Coronavírus foi a instalação de um hospital de campanha que iniciou com 18 leitos e a chegada de 15 profissionais entre médicos e enfermeiros enviados pelo Ministério da Saúde para a capital do estado.

$\mathrm{Na}$ esfera federal brasileira, as divergências entre o Ministério da Saúde que recomenda o isolamento social para diminuir o contágio e os discursos e ações do Presidente da República que minimiza a doença e suas consequências, colaboraram para uma crise política que culminou na demissão do Ministro de Estado da Saúde do Brasil, Luiz Henrique Mandetta, no dia 16 de abril de 2020.

O aumento na quantidade de casos e mortes pela Covid-19 na fronteira Brasil-Colômbia revela a emergência desses espaços nas rotas da globalização e evidencia sua interdependência com outros centros regionais, nacionais e internacionais. Não obstante sua interiorização em meio à Floresta Amazônica, pode-se confirmar suas conexões com o fluxo mundial de passageiros possibilitada pelos aeroportos internacionais instalados em seus territórios, confirmando a assertiva de Lanni (2010, p. 186) que: "de fato cresce mais do que nunca a interdependência. As nações e nacionalidades, assim como os indivíduos e as coletividades, tornam-se mais interdependentes do que nunca". 


\section{CONSIDERAÇÕES FINAIS}

Apesar das medidas mais radicais adotadas pelo governo federal da Colômbia e da prefeitura de Leticia, o ritmo de crescimento de casos da Covid-19 neste local se assemelha às estatísticas da cidade brasileira de Tabatinga. Nos últimos dias, Leticia apontou a proximidade com sua cidade-gêmea brasileira e as medidas menos rigorosas de combate ao Coronavírus adotadas pelo Brasil para pressionar o governo colombiano a apoiar o município, que sofre com a precariedade do sistema de saúde público, mobilizando profissionais de saúde, aparelhos respiradores e implementação de mecanismos de biossegurança, além do envio de militares para monitoramento da fronteira com o objetivo de diminuir a propagação do vírus.

Até o momento, não foram verificadas medidas de integração oficias, entre as cidades-gêmeas de Tabatinga e Leticia, para o combate do novo Coronavírus. Tal cenário deveria ser debatido entre os representantes do poder público e das autoridades de saúde mesmo antes da confirmação dos primeiros casos da doença, com a finalidade de evitar a expansão da Covid-19 e a sobrecarga de seus sistemas de saúde.

Conforme afirmar Haesbaert (2020) temos muitas lições geográficas a aprender nesses tempos de pandemia da Covid-19. Nas cidades-gêmeas de Tabatinga e Leticia na fronteira amazônica não é diferente. As normas, representadas pelos decretos federais, estaduais/departamentais e municipais, ainda que temporárias, exprimem novas configurações ao espaço restringindo o fluxo aéreo e a circulação de pessoas nos limites territoriais, modificando também grande parte da cadeia produtiva e de consumo associadas com o objetivo de combater um vírus globalizado. As mídias sociais das duas cidades são alimentadas diariamente com informações, mapas, gráficos sobre os novos casos e óbitos da doença ao mesmo tempo que buscam incentivar o distanciamento e isolamento social.

Apesar das duas cidades estarem distantes dos grandes centros urbanos, seus fixos (aeroportos) permitem grande fluxo (passageiros e cargas) e integração entre esses espaços e suas respectivas metrópoles. Essa dinâmica, sem dúvidas, colaborou para a inserção desses municípios nas estatísticas da Covid-19, em que simultaneamente Tabatinga se destaca na escala estadual e Leticia também apresenta aumento no número casos.

A paisagem urbana, nessa pequena porção no interior da imensidão da Floresta Amazônica, agora está mudada, menos poluição atmosférica e sonora, diminuição do tráfego intenso de motocicletas (talvez não o suficiente), mas também menos trocas transfronteiriças que reúnem no mesmo chão brasileiros, colombianos, peruanos, povos indígenas e turistas. Enfim, a pandemia da Covid-19 revela-nos o quão integrado estamos ao processo de globalização, confirmando essas cidades como "nós das redes de relações", apesar da percepção de isolamento que pode transparecer devido às distâncias físicas dos grandes centros de decisão e de poder.

As crescentes confirmações de infectados e óbitos nestas cidades, a possível subnotificação diante do não-diagnóstico de vários casos assintomáticos, e as projeções feitas pelas autoridades de saúde de que o pico da doença ocorra no mês de junho nos permite continuar analisando o fenômeno na região com a expectativa de que as medidas aqui apresentadas contribuam para o achatamento da curva da Covid-19 e seus efeitos sobre os sistemas de saúde nessa fronteira amazônica.

\section{REFERÊNCIAS}

AEROCIVIL. Estadísticas Operacionales - Aerocivil. Disponível em: $<$ http://www.aerocivil.gov.co/atencion/estadisticas-de-las-actividades-aeronauticas/estadisticas-operac ionales>. Acesso em 25 Abril 2020.

AMAZONAS [Brasil]. Decreto $n .^{\circ}$ 42.087, de 19 de março de 2020 . Dispõe sobre a suspensão das aulas da rede pública estadual de ensino, em todos os municípios do Estado do Amazonas, bem como das atividades das academias de ginástica e similares, e do transporte fluvial de passageiros em embarcações, à exceção dos casos de emergência e urgência, na forma que especifica. Manaus:

Gabinete do governador do estado do Amazonas [2020]. Disponível em: $<$ http://www.defesacivil.am.gov.br/wp-content/uploads/2020/03/Decreto-42.087-de-19-de-mar\%C3\%A 7o-de-2020.pdf>. Acesso em 25 de abril de 2020. 
AMAZONAS [Colômbia]. Decreto n. ${ }^{\circ}$ 084, de 20 de Marzo de 2020. Por la cual se convoca a un aislamiento preventivo y voluntatio por la vida. Leticia: Departamento del Amazonas. [2020a]. Disponível <https://amazonas.micolombiadigital.gov.co/sites/amazonas/content/files/000742/37057_decreto-0084 -de-20-marzo-2020-v2.pdf>. Acesso em 24 de Abril de 2020.

AMAZONAS [Colômbia]. Decreto n. 099 de 08 de Abril de 2020. Por el cual el gobernador del departamento de Amazonas adopta las directrices del decreto legislativo n. ${ }^{\circ} 531$ del 8 de abril de 2020. Leticia: Departamento del Amazonas [2020b]. Disponível em: <https://amazonas.micolombiadigital.gov.co/sites/amazonas/content/files/000758/37860_decreto-0099 .PDF>. Acesso em 25 de Abril de 2020.

ANTAQ. Angência Nacional de Transporte Aquaviário. Caracterização da oferta e demanda do transporte fluvial de passageiros e cargas na região na região amazônica. Belém: ANTAQ, 2013.

BECKER, Bertha. Geopolítica da Amazônia. Estudos avançados. vol.19 no.53 São Paulo Jan./Apr. 2005. Disponível em: <http://www.scielo.br/pdf/ea/v19n53/24081.pdf> Acesso em: 25 de abril de 2020. https://doi.org/10.1590/S0103-40142005000100005

BENTO, Fabio Régio. O papel das cidades-gêmeas de fronteira na integração regional Sul-Americana. In: Revista Conjuntura Austral, Vol. 6, n. ${ }^{\circ} .27$ - 28 Dez. 2014 - Mar. 2015, p. 40-53. https://doi.org/10.22456/2178-8839.51125

BRASIL. Portaria n. 125 , de 21 de março de 2014. Estabelece o conceito de cidades-gêmeas nacionais, os critérios adotados para essa definição e lista todas as cidades brasileiras por estado que se enquadram nesta condição. Diário Oficial [da] República Federativa do Brasil, Brasília/DF, 26 mar. 2014 Anais do II Simpósio Internacional Pensar e Repensar a América Latina ISBN: 978-8-7205-159-0 15.

BRASIL. Portaria n. ${ }^{\circ} 125$ de 19 de Março de 2020. Dispõe sobre a restrição excepcional e temporária de entrada no País de estrangeiros oriundos dos países que relaciona, conforme recomendação da Agência Nacional de Vigilância Sanitária - Anvisa. Brasília: Presidência da República.[2020a]. Disponível em: <www.in.gov.br/en/web/dou/-/portaria-n-125-de-19-de-marco-de-2020-248881224>. Acesso em 25 de Abril de 2020.

BRASIL. Portaria n. ${ }^{\circ} 152$ de 27 de Março de 2020. Dispõe sobre a restrição excepcional e temporária de entrada no País de estrangeiros, conforme recomendação da Agência Nacional de Vigilância Sanitária - Anvisa.. Brasília: Presidência da República.[2020b]. Disponível em: <www.in.gov.br/en/web/dou/-/portaria-n-152-de-27-de-marco-de-2020-250060288 1/2>. Acesso em 25 de Abril de 2020.

BRASIL. Boletim Epidemiológico Especial COE Covid-19 n. 14. Secretaria de Vigilância em Saúde Ministério da Saúde. 26 de Abril de 2020 [2020b], Disponível em:<https://portalarquivos.saude.gov.br/images/pdf/2020/April/27/2020-04-27-18-05h-BEE14-Boletimdo-COE.pdf>. Acesso em: 27 de Abril de 2020.

COLÔMBIA. Decreto n. 412 de 16 de Marzo de 2020. Por el cual se dictan normas para la conservación del orden público, la salud pública y se dictan otras disposiciones. Bogotá: Presidencia de la Republica [2020a]. Disponível em: <https://dapre.presidencia.gov.co/normativa/normativa/DECRETO\%20412\%20DEL\%2016\%20DE\%2 OMARZO\%20DE\%202020.pdf>. Acesso em 25 de abril de 2020.

COLÔMBIA. Decreto n. 457 de 22 de Marzo de 2020. Por el cual se imparten instrucciones en virtud de la emergencia sanitaria generada por la pandemia del Coronavirus Covid-19 y el mantenimiento del orden publico. Bogotá: Presidencia de la Republica [2020b]. Disponível em: <https://id.presidencia.gov.co/Documents/200323-Decreto-457.pdf>. Acesso em 26 de abril de 2020.

DANE. Departamento Administrativo Nacional de Estadística. Serie de proyecciones de población con desagregación nacional, departamental, municipal, y cabecera - resto (centros poblados y rural disperso). <http://www.dane.gov.co/files/investigaciones/poblacion/proyepobla06_20/Edades_Simples_1985-202 0.xls>. Acesso em 25 Abril de 2020.

EUZÉBIO, Emerson Flávio. Fronteira e Horizontalidade na Amazônia: As cidades gêmeas de Tabatinga (Brasil) e Leticia (Colômbia). ACTA Geográfica, Boa Vista, v.8, n.18 set./dez. de 2014. pp.1-19. https://doi.org/10.4000/confins.9659

DOl:http://dx.doi.org/10.14393/Hygeia0054531 Hygeia Edição Especial: Covid-19, Jun./2020 p.221-230, pág.229


FARIAS, Heitor Soares. O avanço da Covid-19 e o isolamento social como estratégia para redução da vulnerabilidade. Espaço e Economia [Online] 17, 2020 Disponível em: <http://journals.openedition.org/espacoeconomia/11357>. Acesso em 24 de Abril de 2020. https://doi.org/10.4000/espacoeconomia.11357

FVS. Amazonas tem mais de 1.200 pacientes fora do período de transmissão do novo Coronavírus. Fundação de Vigilância em Saúde do Amazonas. Disponível em: <Amazonas tem mais de 1.200 pacientes fora do período de transmissão do novo Coronavírus>. Acesso em 26 de abr. 2020.

HAESBAERT, Rogério. Reflexões geográficas em tempos de pandemia. Espaço e Economia [Online], 18|2020. Disponível em: <http://journals.openedition.org/espacoeconomia/1182> Acesso em 26 de Abril de 2020. https://doi.org/10.4000/espacoeconomia.11826

HENRIQUE, Guilherme. Os desencontros de Bolsonaro e governadores na pandemia. Nexo Jornal, $2020 . \quad$ Disponível em: $<$ https://www.nexojornal.com.br/expresso/2020/03/20/Os-desencontros-de-Bolsonaro-e-governadores -na-pandemia>. Acesso em 24 de Abril de 2020.

IANNI, O. Teorias da Globalização. 16ª ed. Civilização Brasileira: Rio de Janeiro, 2010

IBGE. Cidades e Estados - População estimada. Instituto Brasileiro de Geografia e Estatística. Tabatinga: acesso em 25 de Abril de 2020. Disponível em: https://www.ibge.gov.br/cidades-e-estados/am/tabatinga.html

INFRAERO. Características aeroporto de Tabatinga. Disponível em: $<$ https://www4.infraero.gov.br/aeroportos/aeroporto-internacional-de-tabatinga/sobre-o-aeroporto/cara cteristicas/>. Acesso em 25 de Abril de 2020.

LETICIA. Decreto $n .^{\circ} 47$ de 30 de Marzo de 2020. Por la cual se adoptan nuevas medidas sanitarias frente a la declaratoria de emergencia sanitaria por causa del coronavirus Covid-19. Leticia: Alcadia del Municipio de Leticia [2020a]. Disponível em: <http://www.leticia-amazonas.gov.co/noticias/decreto-0047-del-30-de-marzo-de-2020>. Acesso em 26 de abril de 2020.

LETICIA. Decreto n. ${ }^{\circ} 59$ de 26 de Abril de 2020. Por el cual se adopta el aislamiento preventivo, obligatorio de todas las personas que habitan en el municipio de leticia de conformidad con el decreto n. ${ }^{\circ} 593$ de 2020 y se imparten instrucciones para su debida ejecución. Leticia: Alcadia del Municipio de Leticia [2020b]. Disponível em: $<$ http://www.leticia-amazonas.gov.co/noticias/decreto-0059-del-26-de-marzo-de-2020>. Acesso em 26 de abril de 2020.

OPAS BRASIL. OMS afirma que COVID-19 é agora caracterizada como pandemia. Organização Pan-Americana de Saúde. 11 de Mar. de 2020. Disponível em: $<$ https://www.paho.org/bra/index.php?option=com_content\&view=article\&id=6120:oms-afirma-que-cov id-19-e-agora-caracterizada-como-pandemia\&Itemid=812>. Acesso em 24 de Abril de 2020.

SILVERMAN, Hollie. The US has at least 963,168 coronavirus cases. CNN. April 26, 2020.[2020] Disponível em: $<$ https://edition.cnn.com/world/live-news/coronavirus-pandemic-04-26-20-int//index.html>. Acesso em 27 de abril de 2020.

TABATINGA. Decreto $\mathbf{n} .^{\circ} 104$ de 17 de Março de 2020. Dispõe sobre a decretação de Estado de Alerta na saúde pública do município de Tabatinga, em razão da pandemia mundial do novo Coronavírus 2019 (Covid-19) e institui o comitê intersetorial de prevenção ao Covid-19. Tabatinga:

Prefeitura Municipal de Administração [2020a].

TABATINGA. Decreto n. ${ }^{\circ} 142$ de 17 de Abril de 2020. Altera o Decreto n. ${ }^{\circ} 138 / G P-P M T$ de 15 de Abril de 2020 bem como adota outras medidas a serem cumpridas em razão da pandemia mundial do novo Coronavírus 2019 (Covid-19). Tabatinga: Prefeitura Municipal de Administração [2020b].

TABATINGA. Decreto n. ${ }^{\circ} 132$ de 8 de Abril de 2020. Decreta situação de Emergência na saúde pública de Tabatinga e define novas medidas de contenção, em razão da pandemia mundial do novo Coronavírus 2019 (Covid-19). Tabatinga:Prefeitura Municipal de Administração [2020c]. 